\title{
Pedagogia da Paz: uma proposta dialógica
}

\author{
Alessandra Maria Martins Gaidargi ${ }^{1}$ \\ Orcid: https://orcid.org/0000-0001-5626-5436
}

\begin{abstract}
Resumo
O presente artigo traz a proposta da Pedagogia da Paz alicerçada nos conceitos de Paulo Freire sobre o diálogo e a "justipaz", resultante de pesquisa de pós-doutorado acerca de culturas de paz e educação a partir dos princípios freirianos, realizada entre 2019 e 2020. A Pedagogia da Paz é composta pelas exigências nas relações entre homens e mulheres no mundo e na escola para que possam alcançar um estado de paz em movimento permanente, capaz de transformação de sujeitos no caminho da emancipação, conscientização e libertação. Dividido entre o conceito das relações de paz, as relações de paz na escola e as relações de paz entre os educadores, este estudo de caráter teórico bibliográfico busca lançar luz sobre as possibilidades de promoção de paz dialógica na educação, onde meninos e meninas, homens e mulheres, possam estar sendo em paz enquanto, em comunhão, recriam o mundo a partir da educação.
\end{abstract}

Palavras-chave: Educação. Cultura de Paz. Dialogicidade.

\begin{abstract}
This article presents the Pedagogy of Peace proposal based on Paulo Freire's concepts of dialogue and "justipaz", resulting from the postdoctoral research on cultures of peace and education based on the Freirian principles, held in 2019-2020. Pedagogy of Peace is composed by the demands in the relations between men and women in the world and in the school so that it can reach a state of peace in permanent movement, capable of transforming the subject in the path of emancipation, awareness and liberation. Divided between the concept of peace relations, peace relations at school and peace relations between educators, this study theoretical seeks to shed light on the possibilities of promoting dialogical peace in education. It is about boys and girls, men and women, possibilities of being at peace while, in communion, recreate the world from education.
\end{abstract}

Keywords: Education. Peace. Dialogicity.

\footnotetext{
${ }^{1}$ Pós-doutora em Educação pela Universidade Nove de Julho, São Paulo, SP. Conferencista na International Peace Conference 2020, sediada pela Universidade de Berkeley. Doutora em Educação - Linha de Pesquisa Teorias, Políticas e Culturas e Mestre em Educação - Linha de Pesquisa Teorias e Políticas em Educação pela Universidade Nove de Julho, São Paulo, SP. Especialista em Formação de Professores para o Ensino Superior e Master em Comunicação pela Universidade Paulista, São Paulo, SP e Launching Innovation in Schools pelo MIT e Data Wise: Collaborative Process to Improve Learning and Teaching por Harvard, Cambridge, Massachussetts, Estados Unidos. Bacharel em Comunicação Social e Licenciada em Pedagogia pela Universidade Cruzeiro do Sul, São Paulo, SP. E-mail: alessandra.gaidargi@gmail.com.
} 


\section{Introdução}

E se o único caminho para a educação em paz for a revolução? Paz é substantivo feminino, situação de ausência de conflito ou problemas, mas esse cenário de fato existe para além da definição teórica quando consideramos a educação como movimento de emancipação e libertação?

O ser humano é singular, cada um tem suas necessidades e vontades. Para muito além das diferenças físicas os seres humanos diferem em sua própria humanidade. O mesmo aspecto que torna todos os homens e mulheres participantes de um mesmo grupo, sua capacidade intelectual, cognitiva e emocional, é o que os torna radicalmente diferentes uns dos outros. Ainda que o pensamento seja a semelhança entre todos os seres humanos, o pensar os torna todos únicos em sua condição de mulheres e homens no mundo.

Se as diferenças são, então, o que determina a humanidade, é razoável almejarmos um estado de bem-estar coletivo, de paz, a partir da extinção absoluta do conflito e das diferenças? Se ninguém é igual e, logo, ninguém pensa igual, isso se demonstra impossível. A proposição de cenários em que todos os homens e mulheres pensem e sejam iguais é a origem da guerra, visto que as diferenças humanizam homens e mulheres. Entretanto, quando compreendemos a paz como a negação da violência e não da diferença, do desrespeito e não necessariamente do conflito que faz parte da vida humana (GUIMARÃES, 2005; JARES, 2002), começamos a traçar o caminho da paz possível. Neste ensaio teórico, de caráter bibliográfico, são apresentados os conceitos freirianos relacionados à paz e tecidas reflexões e propostas acerca da paz que acontece, a todo o tempo, enquanto homens e mulheres se relacionam.

Considerando então que a paz enquanto ausência absoluta de conflitos é objetivo metafórico e inalcançável, visto que enquanto houver mulheres e homens haverá diferença e enquanto houver diferença haverá conflito, há que se encontrar um inédito-viável para a paz possível, que talvez resida no próprio conflito e na maneira que a humanidade se propõe ao debate das diferenças. Uma das bonitezas de ser gente, como nos traz Freire (2011a), é a possibilidade e o dever de brigar por aquilo que se crê.

É importante conceituar a necessidade do embate de ideias porque paz não é sinônimo de resignação (FREIRE, 2011a) e existe para além da guerra, não podendo ser considerada simplistamente como seu oposto adequado. A paz possibilita a um humano enxergar o outro como par a partir da manutenção do conflito de ideias na esfera do respeito. "A paz não é a ausência da diferença, é a coroação do diálogo entre os pares. A paz é dialogia" (GAIDARGI, 2020, p.30).

Do diálogo que possibilita a compreensão das diferenças e sua discussão apartada da violência emerge a paz, estado em que homens e mulheres existem em comunhão. Esta é a premissa de uma educação em paz, aprender em comunhão mediatizados pelo mundo. Só há paz mundial quando há paz nos homens e nas mulheres, a paz em relação só é possível quando há paz interna nos homens e mulheres porque a paz se faz em troca. É impossível "estar sendo" em paz de maneira solitária uma vez que o diálogo implica a relação.

Lutar pela paz é legítimo e dissociado de qualquer violência, é confrontação justa por soluções respeitosas para os conflitos. Legítimo e exigência imperiosa dos tempos atuais (FREIRE, 2000). A paz não precede a justiça, de fato constrói-se pela justiça, no diálogo. A humanidade é exercida em busca da justipaz ${ }^{2}$, luta justa pela dignidade humana, mas a paz em movimento vai além disso, reside na construção e manifestação de culturas de paz, onde se traduza no fazer e no ser de homens e mulheres em todas as suas relações. A paz é um estado de ser dialógico por ser um caminho a ser trilhado e, não, um estado fim.

\footnotetext{
${ }^{2} \mathrm{O}$ conceito de justipaz, a paz pela justiça, é freiriano e traduz ações de movimentos sociais e humanos pela justiça social, na lógica de poder contra-hegemônica (GADOTTI, 2009).
} 
A realidade total da existência humana pode ser interpretada de várias formas, a partir das impressões de cada sujeito, que vê e lê o mundo de sua própria maneira. A transmutação relacional da natureza em ambiente simbólico/significante é única de cada sujeito e decorre das relações humanas mediatizadas pelo mundo, possibilitando que os sujeitos percebam os sentidos de sua existência. Estando a vocação ontológica humana baseada na incompletude e no inacabamento do homem (FREIRE, 2011b), a humanidade acontece no vir-a-ser, na mudança a partir de novas leituras de mundo que se desenvolvem a partir do diálogo com o outro.

$\mathrm{O}$ que permite às mulheres e aos homens apoderarem-se de sua humanidade é a compreensão de si, processo transformativo baseado no diálogo com o outro e com seu próprio arcabouço de ideias. "Da dialogicidade do homem e do mundo renascem, continuamente, o homem e o mundo. Em sua constante transformação, o homem se humaniza. O caminho para a paz é, portanto, a própria consagração da paz" (GAIDARGI, 2020, p. 38).

\section{A Paz Dialógica}

A ausência total de divergência faz-se inconcebível num mundo humano que é movido, exatamente, pelas diferenças que, por sua vez, sempre existirão como condição para a própria existência humana. Sendo assim, o caminho da paz possível é o de enfrentamento das diferenças a partir do diálogo, da comunhão entre os sujeitos. Paz e liberdade caminham lado a lado, e a liberdade se dá em relação: ninguém liberta ninguém, e ninguém se liberta sozinho, homens e mulheres se libertam em comunhão (FREIRE, 2011a).

Refletir criticamente sobre seu lugar no mundo leva mulheres e homens ao cerne de sua humanidade, que é própria e tem vida. Cada um tem sua verdade, individual e legítima. Ainda assim é possível a paz quando os pensamentos diferentes se complementam, quando em comunhão os seres humanos se propõem a dialogar em estado plural de respeito à liberdade de cada um. Da comunhão resulta a libertação que abre o caminho para o estar sendo em paz.

A desumanização é ocasionada pela opressão, pela falta do diálogo, e ao distanciar homens e mulheres de sua matriz humana estes tornam-se violentos e afastam-se da ética humana necessária. A alienação de seu próprio ser no mundo retira do ser humano a possibilidade de assenhorar-se de sua humanidade. A humanização é pressuposto para a existência da paz.

O diálogo nasce do encontro entre os sujeitos (FREIRE, 2011b). O diálogo que se traduz em paz acontecendo, com mulheres e homens sendo mulheres e homens em processo contínuo de troca, está muito além da conversa: é categoria universal de comunicação e independe do encontro físico. Estabelece-se a partir do momento em que os sujeitos se colocam no mesmo campo emocional (id., ibid.). Diálogo é fala e também escuta, com o mesmo peso, trocando fragmentos de mundo.

O exercício da argumentação sobre sua visão de mundo acontece, para homens e mulheres, a partir do diálogo que os coloca como sujeitos de suas próprias histórias. Todos os seres humanos têm condições de expor sua leitura de mundo enquanto pares, do respeito a essa humanidade compartilhada emerge a transformação. "Dialogar é pronunciar o mundo que é seu, do qual se apropriou pela consciência de sua existência" (GAIDARGI, 2020, p. 42).

A paz dialógica, entretanto, não se resume ao conflito. Pelo contrário, ela tem seu berço no encontro, na fusão de ideias. Até mesmo quando abraça o conflito não se baseia em imposição, apenas em contraposição de ideias e ideais. Para Freire (2011b) o diálogo é o uso da 'palavra', é ação e reflexão inextricavelmente unidas. Ao comunicar e dividir o mundo com o outro, o ser humano avança para a libertação em comunhão, num caminho de paz dialógica. Dialogar é mais que dividir seu mundo, dialogar é criar um mundo a partir da coexistência. 
Considerando a importância da troca para que se estabeleça uma relação de paz dialógica, a humildade no diálogo se faz primordial. Diálogo é tarefa para aqueles que conseguem se compreender pares em humanidade. A arrogância do saber mais ou saber melhor implica uma relação de poder que não é pertinente ao diálogo e impede a construção de culturas de paz. A arrogância e a alienação transformam os conflitos em atos de violência. De saberes diferentes que se completam ou se contrapõem faz-se a paz dialógica.

Uma das bases do diálogo é a própria fé nos homens e nas mulheres, na capacidade de transcender a posição de oprimidos e buscar a libertação (FREIRE, 2011b). A reciprocidade da fé permite o estabelecimento da paz dialógica, que não é arrogante porque tem fé na humanidade do outro. A fé permite a sinceridade e a consciência de grupo. No entanto esclareça-se que a fé que faz parte do diálogo sincero não é uma fé ingênua ou ligada às doutrinas religiosas, é fé no poder criador humano. É do conhecimento em seu potencial humano que homens e mulheres compreendem que a alienação tira de todos a possibilidade de estar sendo em paz. E, mesmo diante da alienação, o ser humano em busca da paz reconstrói as pontes do diálogo, impulsionado pela fé.

Assim como o ato de fé, a compaixão faz-se necessária no estabelecimento de uma paz dialógica. É imprescindível importar-se humana e profundamente com o outro, com a condição do outro no mundo, a fim de que o diálogo se estabeleça. Essa compaixão não se baseia em dó, ou no sentimento de que o outro é menor portanto precisa de mais cuidado, é a realização de que o outro precisa de cuidado tal qual todos os seres humanos. A compaixão permite compreender que a realidade do outro e suas condições de existência são diferentes, consiste em esforço completamente consciente e comprometido para compreender a dor do outro. Fé e compaixão permitem exercício de paz dialógica desprendida da crença cega na racionalidade, baseado em consciência.

Permitir que homens e mulheres estejam sendo em paz implica a existência de culturas de paz diversas. A busca por modelos culturais em que a paz seja oportunizada é frequente nas sociedades modernas, porém em grande parte não consideram a necessidade do diálogo nesta equação - o que, por si, faz cair por terra a possibilidade de que haja qualquer equação que leve a um resultado de paz. A paz dialógica se faz em culturas que celebram o ser em paz enquanto processo, em frequente movimento de mudança.

Para alcançar a efetividade de culturas de paz dialógica as ferramentas da não-violência se mostram aliadas, visto que os conflitos humanos precisam ser comunicados e trabalhados em formatos que privilegiem o respeito à humanidade do outro. O conceito de não-violência é o de uma forma de luta que leva em conta a manutenção da integridade física e moral dos envolvidos a despeito das diferenças escancaradas por seus conflitos. A existência das revoluções pacifistas de sucesso na história da humanidade demonstra a possibilidade desta filosofia como caminho para culturas de paz dialógicas. Práticas como os círculos de diálogo, comuns entre os indígenas norte-americanos (PRANIS, 2010), são exemplos de como ações de pequenos grupos podem se expandir criando culturas de paz que abraçam sociedade inteiras, em todas as suas esferas sociais e econômicas, auxiliando na reelaboração de conceitos intrínsecos à convivência humana como a relação entre justiça e punição.

Dentro das escolas a instauração de culturas de paz já vem sendo discutida há mais de duas décadas pelas organizações humanitárias mundo afora. A proposta da Unesco para a Educação $^{3}$ é que a eliminação da violência seja um desafio compartilhado por toda a comunidade escolar. Qualificada como não-violência integrada, a proposta tem como intenção conscientizar educadores e outros agentes atuantes na educação de que a partir do diálogo e do compartilhamento de experiências é possível o estabelecimento de uma cultura escolar de paz.

\footnotetext{
${ }^{3}$ Informações disponíveis no site oficial da organização pt.unesco.org
} 
Culturas de paz oportunizam o estar sendo em paz quando consideram a capacidade crítica do ser humano e sua necessidade de exercício do diálogo, tornando-se sujeito de sua própria história. Uma suposta cultura de paz que pressuponha a normatização de comportamentos e a bondade é ingênua e alienante, atuando opostamente a um conceito de paz dialógica. A paz dialógica considera a satisfação das necessidades básicas para que homens e mulheres se sintam humanos e aptos ao diálogo, atuando criticamente na mudança do mundo e compreendendo que sua própria existência está intrinsecamente ligada à existência do mundo. A paz está conectada à existência, e existir envolve cultura, comunicação e linguagem em níveis mais profundos e complexos que aqueles do viver (FREIRE, 2011a).

Para estar sendo em paz dialógica é necessário existir e ser agente de mudança, não apenas viver e contemplar. Contudo, contemplar e agradecer fazem parte do processo de paz interna que reflete no estar sendo em paz relacional. "A gratidão é a paz que está sendo no coração dos homens e mulheres. Gratidão irrestrita à sua condição humana e à possibilidade criadora de, em comunhão, recriar e transformar o mundo, são a manifestação do estado de paz nos sujeitos" (GAIDARGI, 2020, p. 53).

Se a humanidade se desenvolve a partir das relações, e homens e mulheres são seres de relações, compreender a importância das relações e estar com o mundo é inevitável para encarnarem os seres de relações que são (FREIRE, 1967). Sendo assim, quando estão sendo em estado de paz dialógica, os seres humanos são gratos por serem homens e mulheres, em estado de consciência de que a humanidade é que os permite estar ali. Um processo de gratidão que é expansivo, e permite o permanecer sendo em plena humanidade buscando a libertação a partir das transformações que já ocorrem em si e no mundo a partir de sua existência diariamente. A gratidão é a memória moral da humanidade (SIMMEL, 2017), regendo a reciprocidade das relações humanas e tem importante função no equilíbrio social (PIETA; FREITAS, 2009).

Gratidão é movimento individual e coletivo, interligados. É aceitação do desenvolvimento próprio e das relações com o mundo, é aceitação do agir humano em comunhão que oportuniza que homens e mulheres se tornem sujeitos da história que constroem e consolidam de maneira coletiva.

A paz dialógica é um processo humanizante e respeitoso que não obedece a modelo prédeterminado de comportamento de homens e mulheres. A pacificidade nas relações não pode ser confundida, a nenhum tempo, com o impedimento da mudança e da libertação. Ser humano no mundo não é um movimento pacífico, é ação revolucionária, portanto a paz que se propõe dialógica contempla a dimensão da emancipação no estar sendo em paz. E, como sabiamente nos traz Freire (2011b), a revolução é também, em si, um ato de amor, tal qual a paz.

\section{A Paz e a Escola}

A paz é um estado humano, a educação é um caminho para que se aprenda o que é ser em paz e que é possível estar sendo desta maneira. Sem fórmulas mágicas e sem dogmas, ensinar a estar sendo em paz no mundo é ensinar a viver dialogicamente.

Uma proposta educacional de promoção de paz está atrelada à supressão da violência na escola, tanto da violência física dentro dos espaços escolares quanto das violências incutidas nas relações educacionais, muitas vezes relegadas. Propor a paz dialógica dentro da escola supõe o desenho de processos em que toda a comunidade escolar encontre formatos para assegurar respeito à dignidade de todos os sujeitos envolvidos em todas as relações, inclusive aquelas perpassadas por questões hierárquicas de poder.

A paz na escola deve ser construída com base em relações dialógicas, oportunizando aos envolvidos na ação educativa, educadores, educando e demais agentes atuantes na rotina escolar, estarem exercendo sua humanidade em comunhão, em paz. 
Considerando que a prática educativa é especificamente humana, tudo que envolve a educação é também especificidade humana, sendo a escola um resultado das relações humanas que ali se estabelecem. A escola é neutra, não é boa nem má em si (FREIRE; GUIMARÃES, 2003), é uma construção humana e viva que se transforma diariamente a partir dos diálogos que a estabelecem. A paz na escola está intrinsecamente relacionada à ética das relações escolares. Ética que não se faz cínica, nem é suporte para qualquer tipo de discriminação ou acusação (FREIRE, 2011a), que carrega consigo os valores do amor e do respeito, que universalmente regem a convivência humana pacífica.

Se a escola é local de sujeitos em processo de diálogo e libertação, a escola é lugar de conflitos sociais (ARROYO, 2013). A busca pela paz dialógica na escola não admite a ilusão de uma paz sem voz, onde não há espaço de fala para os envolvidos. Visibilidade e entendimento de que sua voz tem espaço são aspectos importantes no movimento de humanização de meninos e meninas, homens e mulheres. Quando a escola se torna um espaço de todos a consciência rebelde dá lugar à consciência crítica (FREIRE; GUIMARÃES, 2014), possibilitando que meninas e mulheres, meninos e homens, se compreendam como sujeitos de sua própria história. Ainda que não haja escola sem problemas, considerar que alguns dos sujeitos que a compõem são um problema é desumanizador. A escola que está sendo em paz é aquela que abraça as histórias de vida e leituras de mundo se seus integrantes.

A paz dialógica atua no contexto sociocultural, sendo a escola, da educação infantil ao ensino superior, um excelente ambiente para que floresça em homens e mulheres o sentimento de pacificidade. Quando se educa para ser em paz existe a preocupação suprema com o aprendizado da humanidade. Estar sendo em paz deriva de uma educação críticoconscientizadora.

A escola que se propõe à paz e ao diálogo é coerente. Traz em suas relações cotidianas os mesmos conceitos de emancipação, empoderamento e justiça social que promove. É uma paz que acontece todos os dias, a todo o tempo, não uma promessa de paz para o dia seguinte.

Quando estão sendo em paz, mulheres e homens, meninas e meninos, se transformam mutuamente sem possibilidade de retorno, sendo a solução dos conflitos a partir do diálogo amoroso a alternativa viável para a construção de um novo paradigma de paz dialógica nas escolas.

O amor deve ser, portanto, eixo central dessa mudança, sendo ele a base fundante de toda a educação. Amor é força motriz da existência humana e possibilita o diálogo. Inexiste o diálogo quando não se manifesta profundo amor ao mundo e aos homens e às mulheres (FREIRE, 2011b). O amor que remete à vocação ontológica do homem, e difere do amor romântico porque é amor à humanidade como um todo, infunda a pronúncia do mundo. E, sendo o amor fundamento do diálogo o é, também, diálogo (id, ibid.). O amor necessário à educação é o que permite a transposição das necessidades individuais e permite compreender a leitura de mundo do outro e dialogar com ela.

Amorosidade é compromisso com o outro, sem o qual a relação entre os sujeitos não pode ser dialógica (FREIRE, 2011b). Amor é potencial humano que permite a mulheres e homens ser no mundo e com o mundo. Para além disto, amorosidade compartilhada proporciona dignidade coletiva por meio de solidariedade e da humildade (FERNANDES apud STRECK; REDIN; ZITKOSKI, 2010), implicando relações dialógicas entre seres humanos. O ato de amor é a valentia no compromisso com a própria libertação e a libertação do outro (FREIRE, 2011b). $\mathrm{O}$ amor permite o ser em paz. Paz e amor caminham juntos.

A afetividade proposta pela amorosidade em Freire não supõe, entretanto, a falta de autoridade. Ela não assusta o educador que se propõe ao diálogo porque ele não teme a visão de mundo do outro. Teme a amorosidade aquele que entende seu saber como uma forma de poder sobre o outro. A afetividade não exclui a cognoscibilidade (FREIRE, 2011a), é possível manter o rigor necessário à docência sem que falte jamais a amorosidade. A prática educacional 
pode ser vivida pelo educador com afetividade e alegria, sem prescindir da formação científica, da rigorosidade e do domínio técnico (Freire, 2011a).

A amorosidade necessária à educação não renega a luta e busca pelo justo. Uma educação que não considere a justa ira contra injustiças e desamor, que luta contra a deslealdade e a exploração, não se faz transformadora ou amorosa, é simplesmente apática. O entendimento da necessidade permanente de luta pela conscientização diz respeito também à amorosidade que se tem com a humanidade. Ainda que a amorosidade não impeça a violência, permite um olhar mais honesto sobre o outro e contribui para a quebra do ciclo da alienação. Só é capaz de enraivecer pelo sofrimento do outro aquele que é capaz de amar.

Uma pessoa não consegue estar sendo em paz se não em liberdade e a educação dialógica tem como finalidade a liberdade e, consequentemente, a paz. A educação dialógica reside na congregação de relações que acontecem dentro de determinado universo escolar pautado em dialogia. Mesmo sendo o diálogo fundamento da educação dialógica; esta o transborda nas relações múltiplas que se estabelecem. Nesse cenário, homens e mulheres não são objetos de estudo de sujeitos externos, estar sendo em conjunto é o próprio objeto de estudo (FREIRE, 2011b).

A capacidade de ter sua própria existência como objeto de estudo torna o ser humano capaz de dialogar e estabelecer a educação dialógica. Enquanto a adesão do animal irracional à sua atividade o torna a-histórico, a compreensão do homem como ser histórico ultrapassa suas atividades. E a paz encontra-se no espaço-tempo histórico próprio da natureza humana. Mulheres e homens podem mudar o mundo porque podem mudar a si mesmos, conscientes dos riscos que correm.

A proposta de uma paz dialógica dentro da escola desde os anos iniciais da educação infantil é fundamental porque quanto mais cedo o diálogo se apresenta aos meninos e meninas, mais revolucionário será (FREIRE, 2011b). Revolução esta que difere da violência e constituise em ato de amor e libertação. A paz é revolucionária, é libertária e é dialógica, acontece na diástase, na transposição. Distante de um estado de harmonia apática, em que a compreensão do futuro não permite sua problematização, a paz que acontece em movimento na educação apropria-se da dialogia para apontar infinitas possibilidades aos sujeitos para a construção de suas relações.

A paz é resultado de tensão coletiva. Se ninguém é sujeito da autonomia de ninguém, ninguém pode ser sujeito da paz de outrem. Ninguém leva a paz a ninguém porque não é algo que se possa dar, é caminho autônomo. Os caminhos para a paz são alcançados em comunhão, não há um educador que "eduque para a paz" se ele não faz a paz enquanto está sendo educador. É possível promover a paz, especialmente a partir próprio ser em paz, mas é impossível ser responsável pela paz do outro, o que leva à compreensão de que o respeito é valor imprescindível para que as relações possam estar sendo em paz.

Respeitar a autonomia e a dignidade de cada aluno é imperativo ético (FREIRE, 2011a), não é favor nem gentileza de professores e professoras com alunos e alunas. Ademais, o respeito entre educadores e educandos é reflexo do amor que alinhava o educar em paz. Ao colocar-se ao lado dos educandos, protegendo-os como um grupo do qual também participa, o educador demonstra afetividade e se conecta, permitindo o diálogo. O que significa que, eventualmente, professores e professoras dialógicos travam brigas com os sistemas estabelecidos a fim de defender os educandos (FREIRE; GUIMARÃES, 2014) e, neste processo, defendem-se a si mesmos e a sua própria autonomia.

O meio não determina o homem, é parte de sua construção enquanto sujeito histórico. Então o respeito à autonomia, à identidade do aluno e à sua dignidade são imprescindíveis ao educador que assume que está sendo, bem como seus alunos e alunas, de acordo com sua própria realidade (FREIRE, 2011b). A partir desse verdadeiro saber se manifesta o respeito mútuo na relação professor-aluno. 
Alunas e alunos trazem consigo, de suas casas, um ideal de paz que precisa ser considerado para que um processo de educação que acontece em paz seja elaborado coletivamente. $\mathrm{O}$ respeito entre educadores e educandos deve estar vinculado à vida e às suas histórias. A educação que supõe a paz dialógica depende de que toda a unidade escolar esteja de acordo com esse objetivo, ciente da imperiosidade do respeito nas relações.

O conceito de paz que meninos e meninas, homens e mulheres, trazem de suas casas é muito importante. Numa educação dialógica o discurso do respeito entre educador e educando deve abranger também a necessidade de construção de pontes de comunicação respeitosa entre escola e família. "O objetivo das relações dialógicas estabelecidas entre o educando e sua família e o educando e seus educadores, de uma perspectiva freiriana e dialógica, é o mesmo: oportunizar sua conscientização de cada um como sujeito de sua história" (GAIDARGI, 2020, p.76). A conexão e a comunicação entre a família e a escola devem ser estabelecidas e cuidadas com respeito e amorosidade, ainda que deva sempre ficar estabelecido que escola não é casa e educação escolar e educação familiar diferem em conceitos e formatos.

O relacionamento com a educação, desde a educação infantil, deve ser cultivado como um processo dialógico. A reflexão sobre os processos educativos, sobre a função da escola e da educação na vida inclusive, deve ser estimulada. Alunos e alunas devem sentir que suas famílias, sejam anteriores ou posteriores, são respeitadas e ouvidas pela escola, tem espaço no ambiente escolar. Ouvir de maneira dialógica, e não apenas escutar as famílias, é ato de paz que demonstra humildade dos educadores e da escola, visto que alunos e alunas são seres integrais e sua existência não se resume às horas que passam no ambiente escolar. Manter uma postura dialógica com o educando supõe a humildade de dialogar com sua família, visto que ninguém sabe tudo e ninguém ignora tudo.

Sobre a relação entre escola e família, é importante esclarecer que coerência não é conivência (FREIRE, 2012), ouvir as famílias não significa adotar suas verdades, apenas respeitá-las sempre que também respeitem os princípios da dignidade humana. A escola pode auxiliar na integração entre escola e vida de crianças e adolescentes a partir do diálogo, sem calar-se frente às violências e, de forma alguma, adotando-as como possíveis em ambiente escolar por estarem sendo perpetradas em ambiente familiar. A escola que é em paz protege e abriga, constitui-se espaço de sujeitos que o constroem a partir do diálogo.

A relação entre escola e família deve ser real e honesta, baseada nas relações que de fato se estabelecem entre os sujeitos envolvidos. De acordo com Freire (2012), num contexto prático-teórico, educação dialógica exige que a escola tenha compreensão concreta do que acontece com educandos e suas famílias. É esse o caminho para compreender o percurso de vida e a visão de mundo de cada aluno e aluna, como tomam consciência de seu papel enquanto pessoas e sujeitos de sua própria história, sejam crianças ou adultos. A educação se estabelece em paz no respeito às diferenças, tornando-se dialógica quando considera o mundo do outro.

Uma vez que educar é intervir no mundo supõe o diálogo com a família, visto que só há como intervir no mundo que conhecemos e o mundo de alunos e alunas se concentra em grande parte em sua própria casa e relações familiares. Quando a escola ignora a história de vida de um aluno ou aluna não honra suas relações amorosas primárias e se fecha para o diálogo sincero. A convivência respeitosa e coerente entre escola e família garante importante passo no caminho do ser em paz dentro da escola.

Apontados todos os aspectos positivos da amorosidade e do respeito na construção de um ambiente escolar onde se possa ser em paz, e esclarecido que educar para o exercício da paz está profundamente ligado à filosofia de não violência, há que se pontuar que a ausência de violência e o cultivo de relações respeitosas e afetivas não podem ser confundidos com ausência de disciplina.

Paz é também ordem. Não a ordem que se refere aos sistemas autoritários, que faz alusão à força, mas a ordem justa que garante o respeito entre as partes, ao espaço do outro. A 
manutenção da ordem na escola é fundamental se desejamos um ambiente de paz, visto que a permissão da liberdade mal centrada, que causa desequilíbrio no contexto pedagógico porque permite desrespeitos, é licenciosidade (FREIRE, 2011a). A liberdade de um acaba exatamente onde começa a liberdade do outro, e o que delimita esse espaço é a justa ordem.

A compreensão adequada do conceito liberdade é desejável desde o início da trajetória escolar, preferencialmente desde o início da vida. Entender o que é a liberdade e quais seus limites protege educandos dos perigos de se tornarem opressores dos próprios educadores e dos colegas, em nome de uma suposta liberdade de ser que se confunde com licenciosidade, que é desmedida. Compreender a possibilidade de ser livre dentro de um sistema ordenado liberta da opressão, permite o entendimento de que há espaço para cada um ser livre e todos devem ser respeitados. Processos educativos em que o equilíbrio de direitos e deveres é explicitado e exercitado, em que os valores são questionados e compreendidos, são o caminho mais efetivo para práticas de paz.

As questões de poder são combustível para a violência escolar e é preciso mais que um discurso dialógico para que seja evitada. A assunção de cada sujeito sobre seu poder e a reflexão acerca de como o utiliza é necessária (FREIRE, 2011a), num processo de mudança em que haja consciência de que se torna opressor sempre que utiliza sua posição de poder para algo que sobrepõe sua reflexão sobre sua prática.

$\mathrm{O}$ respeito dentro do ambiente escolar é bem-vindo e necessário, o medo não. $\mathrm{O}$ medo afasta as pessoas e impossibilita a educação de verdade. Relações educacionais baseadas no medo e a imposição da disciplina que tem como finalidade única evitar a punição são conceitos falidos porque não contribuem com o crescimento pessoal dos educandos. Para se defender da violência declarada e evitar a punição alunos e alunas recorrem às respostas do cérebro reptiliano, lutar ou fugir, o oposto daquelas para as quais a educação deveria levá-los: consciência e busca do que é cognoscível. O autoritarismo acende o medo onde este não deveria tomar o lugar da consciência e da esperança.

A tensão dialógica estabelecida entre autoridade e liberdade desperta o processo do "estar sendo" em paz, entre o conflito inevitável e a resolução dialógica e amorosa com respeito às liberdades dos envolvidos.

\section{A Paz e os Educadores}

Para que seja possível a paz dialógica na escola é imprescindível que haja paz entre os educadores. Há que se fazer a paz dentro da escola para que ela se torne um movimento contínuo, cada educador alcança individualmente a paz enquanto sujeito de sua história e a exercita em seu fazer diário, encarnando a teoria (FREIRE, 2011a). Não é simplista como educar pelo exemplo, é constatação de que só se pode ensinar a ser em paz quando se é capaz de sê-la.

O movimento de paz entre pares educadores é saudável e propulsor de paz, mas não supõe a concordância absoluta em todos os assuntos evidentemente. A paz dialógica se faz entre educadores quando eles se respeitam mutuamente e constroem conhecimento e programas de ensino em comunhão. A amorosidade construída na educação que se faz em paz deve existir também no trato entre colegas professores e professoras.

A paz entre educadores se dá a partir do testemunho autêntico, do pensar certo (FREIRE, 2011a), da busca constante do educador que se propõe a educar para a paz a partir do diálogo. Quando existe a compreensão de ambas as partes sobre o pensar certo do outro e sua práxis é possível estabelecer relações pacíficas e respeitosas. Porém, quando não há humildade sobre a inexistência de um saber único ou quando falta empatia com a posição do outro, a troca de experiências não acontece em diálogo. 
A educação em paz tem início na paz entre educadores porque os sujeitos são a própria paz, não é possível encontrá-la fora do espaço individual que se entrelaça com o coletivo e, também, não há como ensiná-la em relações alheias a si mesmo.

Refletir sobre a prática educativa exige compreender a história de vida do educador e sua relação com os pares. A verdadeira formação docente está impregnada pela criticidade, reconhecendo valores do sujeito educador bem como suas emoções, sua sensibilidade, sua afetividade, sua intuição (FREIRE, 2011a). As interações entre homens e mulheres que se dedicam ao ensino em paz fazem, portanto, parte de sua própria formação, devendo ser pautadas inicialmente por essa mesma paz para possibilitar práxis coletiva. Atuar em relação de respeito aos pares, à própria história e aos educandos em suas particularidades é uma forma de dignificar a própria atividade docente.

Trabalhar a paz dialógica nas escolas a partir das relações entre os educadores é caminho para emergir a consciência. Teoria e prática precisam caminhar juntas para que a educação em estado de paz aconteça. E este processo exige abertura para a transformação, para a troca que colabora para a construção de novos conhecimentos a partir das diferenças. O pensar diferente é, de fato, propulsor da conscientização e, não fossem as diferenças, a própria busca pela paz não faria sentido (JACOB apud FREIRE, 1992). A educação em paz não é, portanto, modelo de igualdade, mas sim caminho para diminuição e compreensão de diferenças a fim de que não se traduzam em práticas de injustiça e opressão.

A paz entre os educadores se faz nas relações entre eles e de cada um com sua própria prática e história pessoal, ao compreender este princípio torna-se clara a necessidade da luta justa pela educação com a qual os educadores se comprometem, mas que pode ser travada de maneira coerente com os ideais dialógicos que dão lugar ao ser em paz. Considerando que a luta é categoria histórica e que a educação é política, tal qual o próprio ato de existir, há que se considerar a reinvenção também histórica de se lutar em paz, proposta por essa pedagogia, como caminho de libertação.

Transformar-se é fundamental para que seja possível o aprender e o ensinar, uma vez que precisamos aprender para além de nos adaptar e sim para transformar e intervir na realidade para recriá-la (FREIRE, 2011a). A paz no âmago das relações entre os professores e professoras proporciona caminhos de transformação efetiva da educação como a entendemos, num modelo dialógico. A transmutabilidade humana permite que homens e mulheres aprendam o tempo todo e ressignifiquem sua existência, permitindo que possam estar sendo em paz.

Educar é uma honra, permite construir junto com mulheres e homens caminhos para o conhecimento, para a autonomia, para a dialogia e para a libertação. Educar é atividade especial e única. Mas essa honra não confere ao professor ou à professora a licença de detentor ou detentora da verdade e do saber puro, devendo a atividade docente estar sempre pautada no respeito à leitura de mundo do outro, seja este outro seu aluno ou seu colega de profissão. Educar em paz pressupõe cuidar para que a vaidade do ego e a arrogância não façam parte de seu fazer.

O educador que se propõe a o ser em paz deve voltar sempre ao papel de aprendiz dos educandos e dos pares educadores, compreendendo também a importância da troca de sabedoria horizontal entre todos os professores e professoras de uma instituição, de uma cidade, de um país. Educadores em conjunto são capazes de estabelecer metas a partir de diálogo, aceitando os saberes do outro de forma respeitosa. Não deve haver lugar para a competição na atividade docente.

Educadores trazem consigo bagagem intelectual e experiência humana valiosa para o trabalho educativo. A falta de horizontalidade na orientação de projetos pedagógicos é um desperdício do conjunto de conhecimentos humanos trazido por cada componente de um corpo docente. Sempre que educadores se colocam lado-a-lado dos colegas fortalecem o professorado 
e esta é uma posição de luta democrática (FREIRE, 2012), uma vez que a luta docente nunca é singular.

A esperança é também muito importante para a paz que acontece em movimento entre aqueles que educam, pois os move em direção à educação dialógica e move, ainda, a humanidade a caminho de evolução. A esperança por um mundo menos violento, injusto e desigual nos exorta à paz enquanto possibilidade no campo da educação, por meio de ação e diálogo.

Homens e mulheres são seres de esperança. Não se faz necessário que se tire os homens e mulheres da desesperança para que aprendam a esperança; só é preciso manter a esperança viva para que não se torne desesperança (FREIRE, 2011a). A esperança não é o que promove a transformação da realidade (FREIRE, 1992), mas é necessária para que a luta ocorra. Esperançosamente se busca por caminhos para a mudança. Mulheres e homens lutam movidos pela esperança, sua prática dá à esperança concretude histórica e não há como prescindir da esperança para "estar sendo" em paz. A luta sem esperança é antidialógica.

São direitos dos professores e professoras amar, ter esperança e crer no ser em paz. Assim como é seu direito a justa raiva e a luta por aquilo em que acreditam. A legitimidade da ira diante da apatia e das injustiças não afugenta o ser em paz, nem o determina ao desamor; pelo contrário guia o homem, a partir do diálogo, ao processo de mudança sendo em paz.

A interpretação e a resposta a realidade total da existência são diversas para cada homem ou mulher e o estado de paz de cada um está relacionado com sua interpretação e compromisso em transformar essa realidade. Se propor a educar é compromisso, consigo, com o outro e com o mundo. Recria-se o mundo ao educar, é comprometimento com a humanidade e não com uma série de conteúdos ou ideologias, porque o ato da educação não é neutro, exige o compromisso. Ao estar no mundo, com o mundo e com os outros, é impossível permanecer em estado de neutralidade (FREIRE, 2011a). O educador pactua com a humanidade ao ensinar, com a sua e com a do outro, para dialogicamente tornarem-se sujeitos de suas histórias. Educar tem propósito, é sempre atividade comprometida.

$\mathrm{Na}$ atuação traduz-se o pensar do docente, seus valores e seus princípios. Uma educação neutra exigiria a total concordância entre os sujeitos, então não poderia se dar no mundo humano. É preciso decidir, como traz Freire (2011a), e romper com o que já não nos traduz para poder comprometer-se com novas ideias. Para estar sendo em paz é preciso romper com a violência, com o autoritarismo, com a arrogância. A paz dialógica se constrói nas relações entre os sujeitos que, em conjunto e comunhão, fazem a educação.

\section{Considerações Finais}

A paz e a educação são temas complementares quando nos debruçamos sobre a escola atual. A temática da paz está presente em currículos da Educação Básica em todo o mundo, mas quase sempre a paz figura como um tema a ser tratado e não um comportamento a ser abraçado por todos os envolvidos na educação. O movimento de conexão entre educação e paz tornou-se assunto científico há pouco tempo (SALLES FILHO, 2019). A paz dialógica, ou a paz que está sendo enquanto os sujeitos estão sendo com o mundo implica compromisso de transformação, limitá-la a um conteúdo a ser estudado ou um projeto a ser posto em prática é limitar a própria dialogicidade a que se propõe.

A partir da paz que acontece dentro de cada sujeito, do movimento pacífico de dialogar com o mundo e seus questionamentos, de lidar com os conflitos sem uso da violência, nasce a paz dialógica entre homens e mulheres. Ser em paz resulta de existências humanas em comunhão, não de vivências ou convivências desconectadas. Da paz que emerge no estar sendo de cada grupo, como as comunidades escolares, constroem-se culturas de paz de sociedades completas. "A paz é o caminho do ser humano para o próprio ser humano. Quando se reencontra 
com sua humanidade, o sujeito é capaz de viver em paz com o outro, porque a humanidade é reflexo. Ser humano é relacionar-se" (GAIDARGI, 2020, p. 36).

$\mathrm{Na}$ educação brasileira há indicativos do reconhecimento de que a educação que promove a emancipação dos sujeitos deve se estabelecer em paz, como no Plano Nacional de Educação 2014-2024 (BRASIL, 2014), que inclui a garantia de políticas de combate à violência e promoção de culturas de paz nas escolas, e na Lei de Diretrizes e Bases da Educação Nacional (BRASIL, 1996), alterada pela Lei n. ${ }^{\circ} 13.663$ (BRASIL, 2018), que inclui a promoção de medidas de conscientização, prevenção e combate a todo tipo de violência, além do estabelecimento de ações que promovam culturas de paz nas escolas. Essas legislações, entretanto, carecem de mais gentileza no trato do assunto, porque a paz é caminho a ser vivido e não pode ser imposto quando se pretende que seja caminho dialógico. $O$ respeito e a autonomia são as margens desse rio.

Refletir sobre uma Pedagogia da Paz é ação crítica e não pauta utópica. A paz na escola reflete as relações entre os sujeitos nesse espaço, o que envolve potencialmente todo o ecossistema humano. Compreender os desdobramentos da paz exige que antes se compreenda a antipaz, o antidiálogo, os mecanismos sociais de opressão e de silenciamento de vozes. Ao propor uma escola que acontece em paz dialógica tocamos no mais radical dos objetivos da educação que é a libertação. É importante salientar que o estar sendo em paz não é simples oposto da educação violenta e autoritária, é muito mais que isso, é uma filosofia de ser, mas está evidentemente em contraposição direta a qualquer tipo de violência, esteja ela situada dentro ou fora dos portões escolares.

Paz é união. É "estar sendo" em conexão. Desmobilizados os sujeitos não podem estar sendo em paz, é ato de união. Diálogo e paz se fazem em movimento contínuo e fluído. $\mathrm{O}$ educador que está sendo em paz demonstra em sua própria existência que todos os que o cercam, colegas e educandos, são suficientemente humanos para que o diálogo possa se estabelecer entre eles. Não há professor ou professora que ensine o diálogo: ou seu fazer é dialógico ou será impossível que transmita essa mensagem. Não há professora ou professor que ensine a paz: se ele está sendo em paz é capaz de trazer todos aqueles que com ele se relacionam para esse movimento, caso contrário estará apenas introduzindo mais um conteúdo vazio em sala de aula.

O estar sendo em paz não é fato dado. Educadores não são em paz um dia e no outro não, é movimento contínuo e transformador, que se retroalimenta permanentemente. A paz se faz enquanto a própria humanidade se reinventa e exige ser refeita nas relações educativas. A paz que nasce do diálogo e da elaboração em comunhão dos conflitos, é o próprio diálogo que gera ou fomenta novos conflitos, que fomenta a emancipação, a libertação e a conscientização. Conscientização essa que se constitui na comprovação da realidade (FREIRE, 2016).

Claramente a orientação de uma educação que esteja sendo em paz tem seus riscos, porém sem riscos não há educação ou existência (FREIRE; GUIMARÃES, 2014). A paz esperançosa que é buscada na escola não é um lugar a se chegar ou uma parada agradável, é movimento de diálogo, resistência aos modelos postos para que haja justiça, transformação de status quo. Educar sendo em paz constitui um inédito-viável, trata-se da proposição de uma realidade ainda não experimentada pelos sujeitos baseada no compromisso do diálogo. Os processos necessários ao inédito viável precisam ser existenciados, sentidos, e não comunicados. A luta de hoje permite o inédito-viável amanhã, então não há caminho senão o da luta para uma pedagogia da paz, para uma proposta de escola que está sendo continuamente em paz - uma paz diferente todos os dias, que se transforma a partir da transformação de seus sujeitos. A autoria coletiva, o estar sendo juntos, faz dos sonhos propostas ineditamente-viáveis.

\section{Referências}

ARROYO, Miguel. Currículo, território em disputa. São Paulo: Vozes, 2013. 
BRASIL. Lei n. 9394, de 20 de dezembro de 1996. Lei de Diretrizes e Bases da Educação Nacional - LDB. Brasília: MEC, 1996.

BRASIL. Lei n. ${ }^{\circ}$ 13.663, de 14 de maio de 2018. Inclusão da Promoção de Medidas de Conscientização, de Prevenção e de Combate a todos os Tipos de Violência e a Promoção da Cultura de Paz entre as Incumbências dos Estabelecimentos de Ensino. Brasília: MEC, 2018.

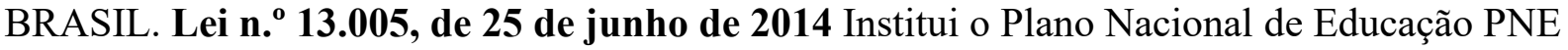
2014-2024. Brasília: Inep, 2014.

FREIRE, Ana Maria Araújo. Educação para a paz segundo Paulo Freire. Revista Educação, Porto Alegre, v. 29, n. 2, p.387-393, mai./ago. 2006.

FREIRE, Paulo. Educação como prática da liberdade. Rio de Janeiro: Paz e Terra, 1967.

FREIRE, Paulo. Pedagogia da esperança: um reencontro com a pedagogia do oprimido. Rio de Janeiro: Paz e Terra, 1992

FREIRE, Paulo. Pedagogia da indignação: cartas pedagógicas e outros escritos. Rio de Janeiro: Paz e Terra, 2000.

FREIRE, Paulo. Pedagogia da autonomia: saberes necessários à prática educativa. São Paulo: Paz e Terra, 2011a.

FREIRE, Paulo. Pedagogia do oprimido. São Paulo: Paz e Terra, 2011 b.

FREIRE, Paulo. Cartas à Cristina: Reflexões sobre minha vida e minha práxis. São Paulo: Paz e Terra, 2012.

FREIRE, Paulo. Conscientização. São Paulo: Cortez, 2016.

FREIRE, Paulo; GUIMARÃES, Sérgio. Partir da infância: diálogos sobre educação. São Paulo: Paz e Terra, 2014.

FREIRE, Paulo; GUIMARÃES, Sérgio. Sobre educação. Diálogos Vol.2. São Paulo: Paz e Terra, 2003.

GADOTTI. Moacir. Fórum Mundial de Educação: proposições para um outro mundo possível. São Paulo: Editora e Livraria Instituto Paulo Freire, 2009.

GAIDARgI, Alessandra Maria Martins. Pedagogia da Paz. São Paulo: BT Acadêmica; Brasília: Liber Livro, 2020.

GUIMARÃES, Marcelo Rezende. Educação para a paz: sentidos e dilemas. Caxias do Sul: Educs, 2005.

JARES, Xésus. Educação para a paz: sua teoria e sua prática. Porto Alegre: Artmed,

PIETA, Maria Adélia Minghelli; FREITAS, Lia Beatriz de Lucca. Sobre a gratidão. Arquivos Brasileiros de Psicologia, Rio de Janeiro, v.61, n.1, p. 100-108, 2009. 
PRANIS, Kay. Processos circulares de construção de paz. São Paulo: Palas Athena, 2010.

SALLES FILHO, Nei Alberto. Cultura de paz e educação para a paz. Campinas: Papirus, 2019 .

SIMMEL, Georg. The sociology of Georg Simmel. Nova Iorque: Andesite Press, 2017.

STRECK, Danilo; REDIN, Euclides; ZITKOSKI, Jaime José. (Orgs.). Dicionário Paulo Freire. Belo Horizonte: Autêntica Editora, 2010. 